\title{
Hiccups in COVID-19: A rare complaint with many possible causes
}

\author{
Gustavo Pinto de Moraes Kiffer, Kelson Gonçalves Cajazeiro, Júlio Sérgio Pedro da Silva and \\ Ricardo Mesquita Camelo* \\ Hospital Unimed Betim, Unimed-BH, Betim, Brazil
}

ORCID: Ricardo Mesquita Camelo: 0000-0001-9025-0289

*Corresponding author: Ricardo Mesquita Camelo, Hospital Unimed Betim, Unimed-BH, Av. Juiz Marco Túlio Isaac, 3400 - Betim Industrial, Betim/MG, 32671-150, Brazil.

To Cite This Article: Gustavo Pinto de Moraes Kiffer, Kelson Gonçalves Cajazeiro, Júlio Sérgio Pedro da Silva, Ricardo Mesquita Camelo. Hiccups in COVID-19: A rare Complaint with many possible Causes. Am J Biomed Sci \& Res. 2021 - 12(5). AJBSR.MS.ID.001788.

DOI: 10.34297/AJBSR.2021.12.001788.

Received: 畊 April 16, 2021; Published: 畊 April 30, 2021

\begin{abstract}
We present a patient convalescing from coronavirus disease 2019 (COVID-19) who developed persistent hiccups. Besides phrenic nerve inflammation due to viral and bacterial pneumonias, medication side effect (e.g., dexamethasone) may be involved in its pathogenesis. Physicians should be aware that the disease itself may not be the only reason for the symptoms their patients may be complaining: side effects of over-thecounter drugs may add some risk to the natural course of COVID-19.
\end{abstract}

Keywords: COVID-19; Persistent Hiccups; Drug side effect

\section{Introduction}

COVID-19 is a recently described disease caused by the SARSCoV-2. [1] The announced risks of morbidity and mortality, without a specific treatment, [1] may be the reason why some patients seek over-the-counter medicines to avoid worsening. Herein we describe a patient convalescing from COVID-19 who developed persistent hiccups (lasting 48 hours to 1 month), after starting over-the-counter drugs.

\section{Case Report}

A previously healthy 50-year-old man had a positive real-time polymerase chain reaction for SARS-CoV-2, after seven days of fever and myalgia. On his first visit to the Emergency Department, physical examination was unremarkable. He was taking amoxicillinclavulanate, azithromycin, and dexamethasone, purchased as over-the-counter medicines. Bilateral peripheral ground-glass opacities were seen in less than $25 \%$ of lung parenchyma by chest tomography (Figure 1). He was discharged home.
He returned three days later, complaining 48-hours hiccups unresponsive to metoclopramide, chlorpromazine, ondansetron, and meclizine. He also complained inappetence and sleep distress. Respiratory and hemodynamic examinations were normal. Lactic dehydrogenase, fibrinogen, and ferritin were high, while electrocardiogram, blood counts, D-dimer, clotting tests, renal function and ions, and liver function were normal. Bilateral peripheral lung ground-glass opacities involved $25 \%-50 \%$ of the parenchyma, associated with consolidation and septal thickening areas (Figure 1). He was admitted to the COVID-19 Unit, receiving intravenous piperacillin-tazobactam, ivermectin due to long-term corticosteroid intake, and thromboprophylaxis. Omeprazole and domperidone were prescribed, to avoid gastroesophageal reflux. Dexamethasone, chlorpromazine, and metoclopramide were maintained. In the next day, chlorpromazine and metoclopramide were withdrawn, due to sedation, while baclofen and gabapentin were started. [2] No fever was noted after 72-hours antibiotics, but hiccups remained. After dexamethasone was changed to prednisone, 
no hiccups were reported. He was discharged home after 7-days antibiotic, with baclofen, gabapentin, and prednisone. Baclofen and gabapentin were withdrawn after 14 days. Prednisone was weaned and withdrawn in 21 days. Two months after hospital discharge, the patient had no complaints. Follow-up chest tomography was normal (Figure 1).

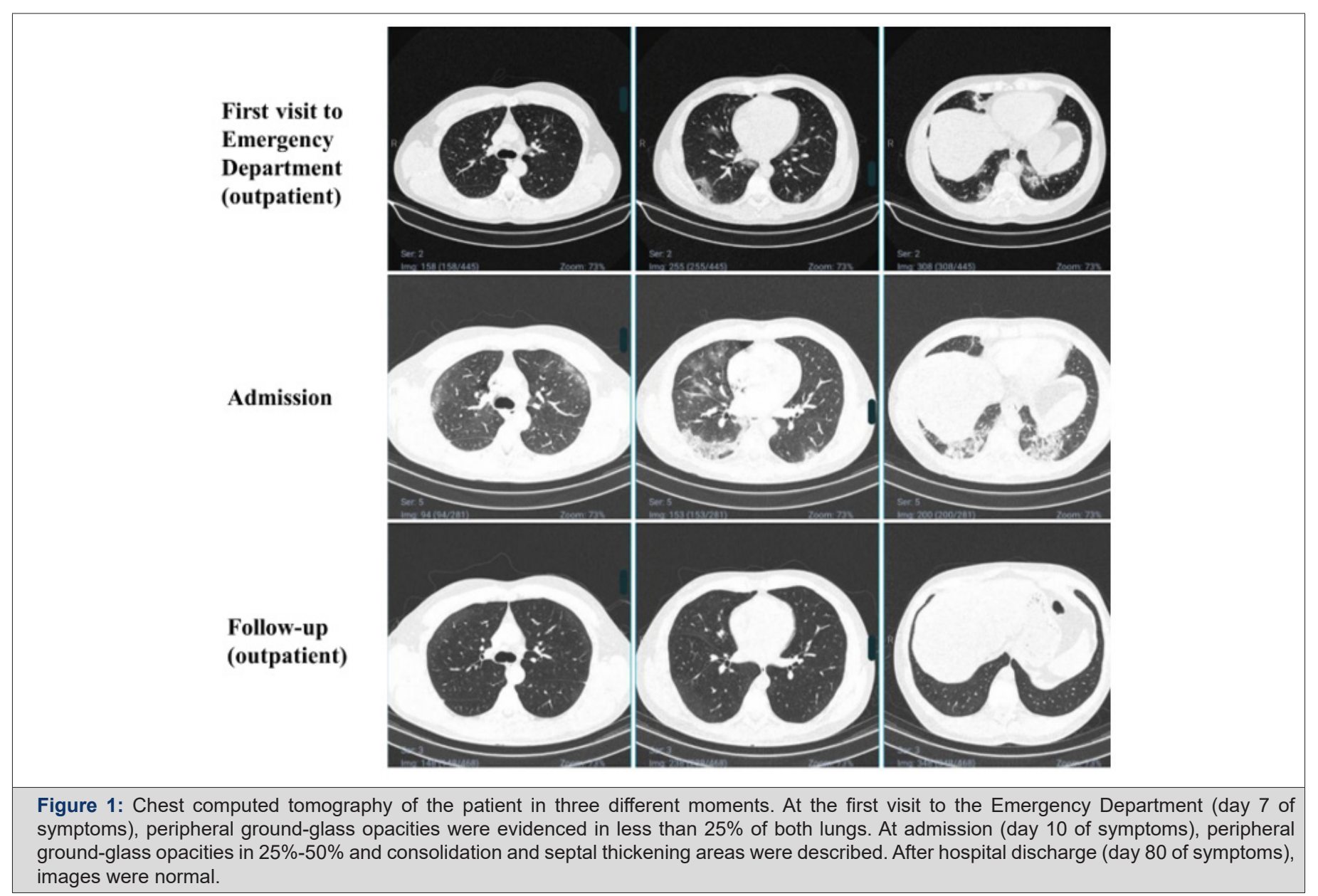

Persistent hiccups or intractable (lasting more than 1 month) hiccups are a rare symptom in COVID-19, but with a significant impact in the quality of life. To our knowledge, this is the third case reported in the literature. [3,4] The first report described a 62-year-old man with viral pneumonia and hiccups lasting four days. [3] He was not taking any additional medicament despite those he used to take for treating chronic diseases. He was admitted with hyponatremia and hypochloremia, and received ceftriaxone, azithromycin, and hydroxychloroquine. Although not mentioned, hiccups were solved within three days. The second report described a 52-year-old man with diabetes and hereditary factor $V$ deficiency who was treated at home with metoclopramide and chlorpropamide for persistent hiccups (duration was not informed). [4]

Based on the aforementioned, cases, $[3,4]$ we considered phrenic nerve irritation secondary COVID-19-associated pneumonia as the main cause for the hiccups, since it is a remarkable cause reported in the literature. [2] Nevertheless, we also considered the side effect of some drugs the patient inadvertently used as another cause for the hiccups. $[2,5,6]$ There are scarce reports of hiccups related to amoxicillin-clavulanate or azithromycin in the literature. [5] However, dexamethasone is known to be related with hiccups. [6] It should be noted that amoxicillin-clavulanate and azithromycin association is not formally indicated to treat COVID-19-associated pneumonia unless a bacterial co-infection is diagnosed. [1] Finally, dexamethasone should be considered for the treatment of people with COVID-19-associated pneumonia who need supplementary oxygen. [1] However, we recognize that the distress of having COVID-19 [7] may have prompted our patient to self-prescribe these drugs, resulting in further distress.

Two important conclusions can be drawn from this case report. Firstly, the myriad of infection/post-infection complications of COVID-19 may be wider than we expected, and hiccups must be included among them. Secondly, physicians should be aware about non-formal anti-COVID-19-indicated drugs their patients are taking because side effects can be troublesome. 


\section{Ethics}

The study was approved by the Committee on Ethics and Research of the Hospital Eduardo de Menezes (CAAE 40139720.3.0000.5124). The enrolled patient signed the Consent Form approving participation in the study. We confirm all patient/ personal identifiers have been removed or disguised so the patient/ person described is not identifiable and cannot be identified through the details of the story.

\section{Funding}

The study received no funding to be planned, implemented, nor published.

\section{Declaration of Interest}

The authors stated that they had no interests which might be perceived as posing a conflict or bias.

\section{References}

1. Khalaf K, Papp N, Chou JT-T, Hana D, Mackiewicz A, Kaczmarek M (2020) SARS-CoV-2: pathogenesis, and advancements in diagnostics and treatment. Front Immunol 11: 1-20.

2. Steger M, Schneemann M, Fox M (2015) Systemic review: The pathogenesis and pharmacological treatment of hiccups. Aliment Pharmacol Ther 42(9): 1037-1050.

3. Prince G, Sergel M (2020) Persistent hiccups as an atypical presenting complaint of COVID-19. Am J Emerg Med 38(7): 1546.e5-1546.e6.

4. Dorgalaleh A, Dabbagh A, Tabibian S, Bahraini M, Rafieemehr H (2020) Persistent hiccups in a patient with mild congenital factor $\mathrm{V}$ deficiency and COVID-19; clinical and laboratory finding of a rare bleeding disorder. Int J Lab Hematol August 43(2): e87-e88.

5. Jover F, Cuadrado JM, Merino J (2005) Possible azithromycin-associated hiccups. J Clin Pharm Ther 30(4): 413-416.

6. Gu YL, Xie JM, Ren J, Cao H, Wei JR, Chen C, et al. (2019) Dexamethasonesparing regimen is an effective and safe alternative in overall antiemetic protection: A systematic review and meta-Analysis. Med 98(39): e17364.

7. Bridgland VME, Moeck EK, Green DM, Swain TL, Nayda D, Matson LA, et al. (2020) Why the COVID-19 pandemic is a traumatic stressor. bioRxiv. 